\title{
Development methodology of the automated networking linguistic resource for commercializing innovation products
}

\author{
Oxana V. Bleikher \\ Department of History and Philosophy of Science and \\ Technology \\ National Research Tomsk Polytechnic University \\ Tomsk, Russia \\ e-mail: iforya@tpu.ru
}

\author{
Natalia V. Trubnikova \\ Department of History and Philosophy of Science and \\ Technology \\ National Research Tomsk Polytechnic University \\ Tomsk, Russia \\ e-mail: iforya@tpu.ru
}

\author{
Vera V. Ageeva \\ Department of History and Philosophy of Science and Technology \\ National Research Tomsk Polytechnic University \\ Tomsk, Russia \\ e-mail: iforya@tpu.ru
}

\begin{abstract}
The article describes the methodology for the development of an automated network linguistic resource for harmonizing thesauruses of scientific, business community and public authorities on the basis of the semantic analysis of communicative situations that arise in the process of development, manufacturing and commercialization of the results of intellectual activity in the field of innovative technologies. The urgency of this problem is due to a pressing need of the Russian science in the improvement of the mechanisms of interaction between representatives of the state institutes of education and science, the scientific community and businesses in the scientific and technological sphere. The authors conclude that the development of such linguistic resource will increase the flexibility of management decisions and enable correction of the situation by scientists and scientific organizations.
\end{abstract}

Keywords-linguistic resource; semantic analysis; administrative barriers; ideological speech genres; thesaurus; innovative technology; scientific discourse; administrative discourse; communicative situation; epistemological dialects; forecasting

\section{INTRODUCTION}

The development of methods of effective interaction between the scientific and business community and public authorities in the process of commercializing innovation products is the actual direction of modern Russian and international sociolinguistics and political linguistics. The urgency of this problem is due to a pressing need of the Russian science in the improvement of the mechanisms of interaction between representatives of the state institutes of education and science, the scientific community and businesses in the scientific and technological sphere.

The observed cognitive dissonance is that solving the governmental task of finding and funding of topical research projects that have high potential for national development, representatives of the administrative apparatus, during the formation of the tender documentation, rely on relevant science epistemological categories, cognitive content and genre form of which, however, have a specific nature, formed in the depths of the administrative bureaucracy system.

A similar situation is observed in the interaction of the academic community with business organizations to engage business in funding for advanced researches. The business community does not hurry to engage in joint projects with state funding because of the administrative barriers caused by the imperfection of the ideological speech genres.

The result is a certain kind of mismatch of substantive content and genre forms describing categories of "method", "tools", "actions", etc. in the administrative discourse, the discourse of research team and the business community discourse. It leads to the low efficiency of the efforts undertaken by the government.

It is necessary to develop a specialized networking linguistic resource that allows setting up a correspondence between the thesaurus of executive authorities, the scientific team and the business community in the commercialization of innovative products. The development of this linguistic automated resource will be aimed at increasing the flexibility of management decisions and the opportunity to correct the situation by the scientists and scientific organizations. 
The aim of the article is to develop the methodology for the development of an automated network linguistic resource for harmonizing thesauruses of scientific, business community and public authorities on the basis of the semantic analysis of communicative situations that arise in the process of development, manufacturing and commercialization of the results of intellectual activity in the field of innovative technologies.

Scientific novelty of the problem is connected with the lack of general works devoted to the complex analysis of the interaction of scientific, business communities and public authorities in the process of commercialization of innovation products and the development of automated networking linguistic resource that will be relevant for Russia, and can increase the efficiency of this interaction. Conducted by authors monitoring of existing information resources and databases on this topic allows to conclude that there is not developed these specialized tools in Russia today.

\section{LIRETATURE REVIEW}

Throughout the 20th century the attention of Russian researchers was attracted by the organization of effective interaction between science and the public authorities which was considered as determining factor of population welfare growth and consolidating the country's geopolitical role.

O.V. Bleikher studies ideological speech genres in the administrative discourse of modern Russia [1]. The author relies on a speech genre theory of M.M. Bakhtin as well as the postmodern interpretation of discourse which suggests studying of speech genres in inter-subject socio-cultural practices: media, public and municipal administration, education, health, culture. O.V. Bleikher identified repeated inconsistencies in the reproduction and disappearance of ideological speech genres in the administrative discourse during the formation of innovation type of organizational culture. The author identified a number of system errors in the sphere of the creation and implementation of innovations. Such problems include: depersonalization, a different understanding of "innovation" by business and scientific community.

Modern Russian research on scientific and authoritative discourse, with rare exceptions, do not go beyond the public discourse and the official order (public authorities' expectations), since the science is within the system of executive power [2]. The authors conducted the analysis of Russian scientific products and revealed a positivist, quantitative bias in the methodology of social sciences, which study scientific and authoritative discourse in modern Russian society.

A number of contemporary authors examine the practice of using critical discourse analysis in the Russian social sciences and humanities, particularly in sociolinguistics, political linguistics and political science. O. M. Morgoon, for instance, stated the deficit practical application of this method by Russian political scientists [3].

Theoretical research in this area has been developed in Peoples' Friendship University of Russia, in particular, special attention is paid to the discursive analysis of the historical and cultural texts, psycho-semantic methods of analysis (a technique of "repertory grids"), narrative analysis. However, there is a methodological asymmetry: despite adequate attention at a theoretical level, critical discourse analysis is not used as a studying tool of specific Russian political and social phenomena, verbalized in the public space.

Modern Anglo-American research on science and authorities discourse comply with the postmodern paradigm, the tendencies of interdisciplinarity and interpretations. A special place in the structure of the methodological apparatus of Western researchers is taken by critical discourse analysis [4; 5]. This method suggested by Norman Fairclough and successfully adapted by number of social sciences and humanities, allows neutralizing the contradiction between the qualitative and quantitative research methods orientation.

The aim of discourse analysis is the study of structural relationships of dominance, discrimination, power and control, real social interactions that take linguistic form. The empirical value of discourse analysis is to focus on the criticism of power relations.

In line with the ideas of T.A. van Dijk, active attention is paid not only to informative aspects, but also to the technique of the political discourse analysis. Methods of semiotic analysis (the study of discourse-frame), as well as the rhetoric and literary criticism (the analysis of a particular discourse-works) are widely used.

Using methodological tools based on critical discourse analysis and systemic functional linguistics, researchers focus on clarifying the textual representations of topical social, political, cultural issues. The critical and reflective function of sociolinguistic discourse analysis is realized due to the diversification of stakeholders interested in the innovative research projects, a variety of funding sources for science.

In the focus of research attention in the sphere of professional communication theory for a long time, there are questions of substantive discourse. This segment of the methodological field attracts so much attention from the $19^{\text {th }}$ to the $21^{\text {st }}$ centuries due to the growing diversity and variability of the structure of modern socio-cultural practices [6;7].

Automated text analysis programs, linguistic patterns and templates to support decision-making for their optimization are an interesting and prospective field of sociolinguistics and political linguistics. The automated processing of definitions of the terms, which are used during the interaction and mutual influence of the discourse of science and the public authorities, is current trend in information technologies for sociolinguistics [8]. Scientists try to develop formats of information which are understandable to all stakeholders from various professional spheres [9].

It makes actual the disclosure of new conceptual research bases and the renewal of existing ones. The need to optimize the interaction between research groups, the business community and the government updates the development of new conceptual bases of such scope of subject discourse as an administrative discourse $[10 ; 11]$. 
Methodological issues of administrative discourse are considered in contemporary socio-humanitarian practice with a number of complementary methodological positions: an interdisciplinary socio-cultural ideological analysis of Teun A. van Dijk; in the context of attempts to integrate the main provisions of linguistics and hermeneutics with the key ideas of social and political science of Jacob Torfing; in the terms of post-structuralism of Jacques Derrida.

However, according to the authors of this article, the relevant basis for the study of the administrative discourse based on the specifics of the Russian intellectual tradition is a poststructuralist discourse analysis presented in the works of Roland G. Barthes, Julia Kristeva, Jacques M. E. Lacan, in which the discourse is seen as a set of social practices, under which new values and meanings are made. In addition, significant are the theoretical positions of Ernesto Laclau and Chantal Mouffe on the indeterminacy of discourse with extradiscourse forces at the level of the economy or the state. It means that such seemingly non-discursive phenomena as "technology", "institutions", "economic processes" are constructed through discursive systems.

Interest in the discursivity of these phenomena increases in the situation of contemporary socio-economic crisis. The specifics of the administrative discourse modes determine the possibility (impossibility) to the diversification and innovation economy, the formation of confidence in the state as a guarantor of social security, the implementation of civil rights and freedoms.

Questions of social constructing administrative discourse are the focus of Western European and Russian scientific and practical research dedicated to public management ideology. In Russia, special attention is paid to the development of appropriate speech ideological discourse genres of executive entities, scientific and business communities. Discursive construction of mechanisms of administrative-legal relations is becoming a determining factor in the effective development of modern Russia in the conditions of instability and uncertainty.

Authors working in different scientific traditions of discourse studies are unanimous in assessing the methodological basis of objective discourse, namely unsatisfactory methodological tools outside the linguistic contexts. Relatively new understanding of discourse disclosed in critical discourse analysis, poststructuralist and postmodernist methodology, and active recovery of Russian domestic traditions of discourse analysis opens up new possibilities for the development of approaches and methods for the study of the administrative discourse.

Identifying concrete problem fields in the methodological basis of the administrative discourse research is based on the analysis of scientific papers about the nature, forms, and methods of implementation of the power in the circuit of public administration, scientific and practical work devoted to understanding the course of administrative reform in Russia [1]. The study of current electronic publications has shown that the limited and imperfect speech ideological discourse genres of administration hinder the realization of the business turnover of the results of administrative achievements.
The authors of the research rely on understanding of the "ideological genre" presented in the works of M.M. Bakhtin. Ideological genre is considered by the authors of the project as "relatively stable thematic compositional and stylistic type of utterance" that occurs as a function of stable, recurring combinations of standard constructs of administrative discourse (the sender, the recipient, the relationship between them, the function of the text, the theme, the subject of the speech, textual material, presentation and expression code) having substantive interpretation. For example, the "request" is a genre of everyday language, in religion it is "prayer", in administrative discourse it is "statement".

Social and cultural research on the experience of administrative reforms in Russia suggest that one reason for "tightening" of these reforms in the administration (in the turnover in the business at the municipal level of conceptual development) is opaque, contradictory and limitations of the ideological genre. In turn, this leads to the formation of a negative image of the reforms, and further it can provoke social complications. Thus, it is necessary to develop the conceptual foundations of management of speech ideological genres of administrative discourse taking into account specific contemporary cultural and historical context.

\section{THEORETICAL FRAMEWORK}

The study of speech ideological genres in the discourse of the scientific community and the public authorities takes a solid niche in the contemporary socio-humanitarian knowledge. It is implemented at the intersection of diverse theoretical and methodological foundations. The proposed interdisciplinary project should be carried out at the intersection of different research strategies: methodological apparatus of the theory of post-industrial society (Alvin Toffler, Manuel Castells); the postmodern discourse theory of Jacques Derrida, Michel Foucault, with the involvement of the special methods of disciplinary-genetic approach of Teun A. van Dijk, Jacob Torfing's theory and the argumentation of socio-cultural approach to the study of the ideological speech genres (M.M. Bakhtin).

The central place in proposed research is occupied by research tools of new intellectual history, new cultural history, political and cultural anthropology, the theoretical arsenal of the linguistic turn and social constructivism. The methodology of "social constructionism" (Norbert Elias, Pierre Bourdieu, David Bloor, Randall Collins) is used to study the objective processes of formation and intellectual legitimization of innovations in society. From the "new intellectual history" it is borrowed the basic principle that the appearance and development of ideas cannot be viewed in isolation from the historical conditions and social forms of intellectual activity, as well as their sources and the main objects of analysis should not be studied in isolation from their historical and cultural context. From poststructuralist theory it is borrowed the concepts of "discourse" and "narrative" that give the priority to forms of textual presentation of the past. The main research methods are multidisciplinary approach, logical and methodological approach and socio-cultural analogy. 


\section{MATERIALS AND METHODS}

To collect the information on the administrative barriers that arise in the interaction of scientific teams, administrative authorities and the business community, interviewing method will be used. For the presentation of the results of the sociological survey it will be used graphical and tabular statistical methods including modern tools to ensure the integrity, accuracy and consistency of information.

To develop the thesauruses of scientific, business communities and the executive authorities in the creation and implementation of innovative technologies, the authors will rely on modern methods of sociolinguistics, semiotic analysis, critical discourse analysis, communicative management. The assessment of economic effects from the use of computer-aided linguistic resource for a particular organization, a subject of the Russian Federation or the Russian Federation as a whole will be carried out by methods of modern economic theory.

The project also involves the active use of interdisciplinary methods. Use of structural content analysis on the basis of keywords and categories allows to reveal invariant sources and to assess their validity. The planned application of the technique of event-analysis of the effective use of ICTresources in the sociological study allows to carry out statistics of a certain order of events repeats, as well as to create forecasts and typology on this basis.

SWOT-analysis of Russian and international approaches to harmonizing thesauri used in different social groups and the communicative situations, will assess their strengths and weaknesses, and to see the consequences of their implementation in everyday practice.

Thus, the novelty of the proposed research approach is a methodological synthesis of highly specialized and interdisciplinary strategies, integrated use of which ensures the achievement of the objectives. The project should be carried out by the forces of the scientific team that united professional competence of historians, linguists, philosophers of science and technology, information technology specialists. The correct combination of research methods social, humanitarian sciences and STEM disciplines will be the basis for a comprehensive analysis of the existing administrative barriers between science, government and business community, and create an innovative automated linguistic resource.

\section{THE PROPOSED RESEARCH STRUCTURE AND DESIGN}

The effectiveness of the interaction of the government and the scientific community depends directly on the nature of mutual changes and mutual stimulation. The main task of state institutions is to identify the problems of national importance while science is called upon to design solutions to specifically identified problems. The result of this interaction becomes the "natural selection" of the best practices and solutions based on the principle of the competition. At the same time, the state corrects the directions and forms of social development based on a scientific approach. The state defines new development tasks.

Any political system involves the formation of power structures in the scientific field, as well as their functional separation, constant diversification of research links with power structures. However, in different countries the share of state intervention in science, a decision-making system in the field of science and technology, research subsidies vary considerably. As a consequence, speech ideological genres of the scientific and administrative discourse vary too.

The structure of the project to create a specialized linguistic resource for harmonizing thesauri of scientific, business communities and authorities implies the following interrelated steps:

- Identification of the administrative barriers that arise in the interaction of scientific teams, administrative authorities and economic entities in the sphere of science and technology, based on a sociological survey of representatives of these communities on the commercialization of intellectual property.

- The development of the thesauri of scientific, business communities and the executive authorities in the field of creation and introduction of innovative products, with systematization of the same and various units of these three thesauri.

- Design, development and testing of an automated system for harmonizing thesauri in the field of development, manufacture and commercialization of innovative technologies.

- The development of practical recommendations to improve the efficiency of interaction of the Russian scientific, business communities and public authorities in the process of commercializing of innovation products.

Detailed description of the proposed research methodology is presented in Figure 1.

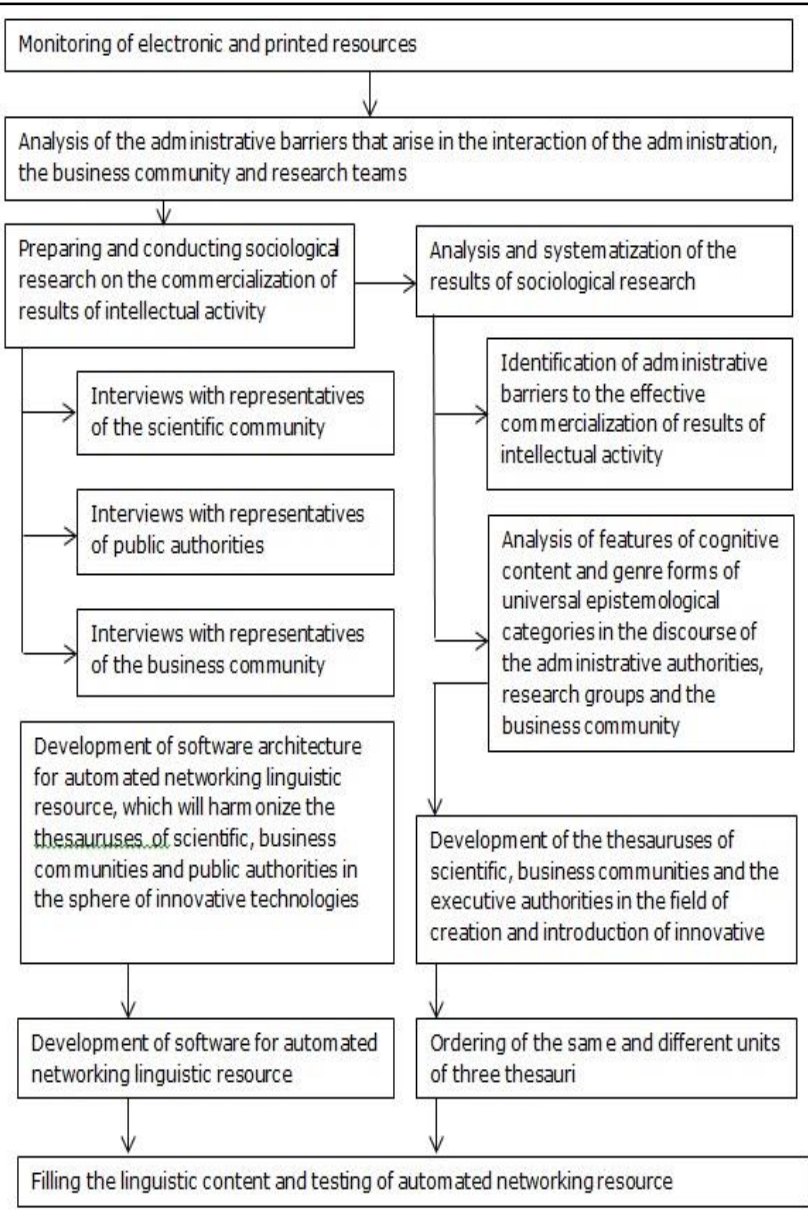


Fig. 1. Proposed research methodology

\section{CONCLUSION}

The development of such linguistic resource will increase the flexibility of management decisions and enable correction of the situation by scientists and scientific organizations. The relevance and the innovative potential of the proposed project are determined by creating a unique tool to overcome administrative barriers in the interaction of executive authorities, the scientific team and the business community in the commercialization of innovative products. Specialized networking linguistic resource will not only improve the efficiency of administrative decisions in the field of innovation policy, but also open to the scientific community the opportunity to neutralize emerging "discourse mismatch" by their own forces.

\section{REFERENCES}

[1] O. Bleikher, and N. Trubnikova, "Use of information technology for the study of conditions for the development of small and medium-sized businesses in the region," Proceedings of 2014 International Conference on Mechanical Engineering, Automation and Control Systems, MEACS 2014. DOI: 10.1109/MEACS.2014.6986906

[2] I.I. Arsentieva, "Scientific discourse of the category "political space": definition, structure, mechanisms of formation," Bulletin of Transbaikal State University, no. 4, pp. 87-93, 2010.

[3] O.M. Morgoon, "Critical discourse analysis within political science research methods," Political linguistics, no. 3(37), pp. 122-128, 2011
[4] A. Rule, J. Cointet, and P.S. Bearman, "Lexical shifts, substantive changes, and continuity in state of the union discourse, 1790-2014," Proceedings of the National Academy of Sciences of the United States of America, no. 112(35), pp. 10837-10844, 2015. doi:10.1073/pnas.1512221112.

[5] M. Bassin, and C. Kelly, Soviet and Post-Soviet Identities, Cambridge University Press, 2012.

[6] J. Misra, "Terminological inconsistency analysis of natural language requirements," Information and Software Technology, no. 74, pp. 183193, 2016. doi:10.1016/j.infsof.2015.11.006

[7] T. E. A. Waters, K. C. Haydon, R. D. Steele, G. I. Roisman, and C. Booth-LaForce, "A linguistic inquiry and word count analysis of the adult attachment interview in two large corpora," Canadian Journal of Behavioural Science, no. 48(1), pp. 78-88, 2016. doi:10.1037/cbs0000035.

[8] A. del-Río-Ortega, M. Resinas, A. Durán, and A. Ruiz-Cortés, "Using templates and linguistic patterns to define process performance indicators," Enterprise Information Systems, no. 10(2), pp. 159-192, 2016. doi:10.1080/17517575.2013.867543.

[9] P.A. Ménard, and S. Ratté, "Concept extraction from business documents for software engineering projects," Automated Software Engineering, 2015. doi:10.1007/s10515-015-0184-4.

[10] J.H. Block, J. Henkel, T.G. Schweisfurth, and A. Stiegler, "Commercializing user innovations by vertical diversification: The usermanufacturer innovator,” Research Policy, no. 45(1), pp. 244-259, 2016. doi:10.1016/j.respol.2015.09.007.

[11] L.H. Heng, M.E. Yusoff, S. Sofian, and N. Norhalim, "Augmenting commercialization of new technology intensive firms," Jurnal Teknologi (Sciences and Engineering), no. 69(6), pp. 63-67, 2014. doi:10.11113/jt.v69.3242. 